
\title{
25 Research Soure \\ Imaging of a siRNA molecular probe targeting MDM2 in breast cancer
}

\section{Xinyu Wang}

Harbin Medical University Fourth Hospital https://orcid.org/0000-0002-8289-7450

\section{Peng Xu}

The First Affiliated Hospital of Harbin Medical University

\section{Yuying Jiao}

The First Affiliated Hospital of Harbin Medical University

\section{Sha Luan}

Harbin Medical University Fourth Hospital

\section{Yue Gao}

Harbin Medical University Fourth Hospital

\section{Changjiu Zhao}

The First Affiliated Hospital of Harbin Medical Universtiy

Peng Fu ( $\sim$ fupeng0451@163.com )

The First Affiliated Hospital of Harbin Medical University https://orcid.org/0000-0002-9860-9150

\section{Research article}

Keywords: MDM2, siRNA, molecular imaging, 99mTc

Posted Date: September 29th, 2020

DOI: https://doi.org/10.21203/rs.3.rs-49584/v1

License: (c) (1) This work is licensed under a Creative Commons Attribution 4.0 International License.

Read Full License 


\section{Abstract \\ Background}

Murine double minute 2 (MDM2) is an oncogene that is important for tumorigenesis, tumor metastasis

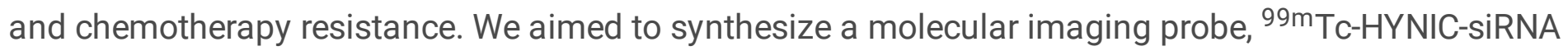
1489 , which could specifically bind to MDM2. The [ $\left.{ }^{99 \mathrm{~m}} \mathrm{Tc}\right] \mathrm{HYNIC}$-siRNA 1489 molecular probe provides an effective way to assess MDM2 expression via SPECT.

\section{Method:}

Three siRNAs were designed and their inhibitory efficiencies were tested using western blots and qRTPCR. The selected siRNA was labeled with the radionuclide 99 m-technetium $\left({ }^{99 m} \mathrm{Tc}\right)$ through the chelator HYNIC. The bioactivity and properties of [ $\left.{ }^{99 \mathrm{~m}} \mathrm{Tc}\right] \mathrm{HYNIC}$-siRNA 1489 were determined before mouse imaging. Imaging and the biodistribution of the probe were used to assess its targeting ability.

\section{Results}

SiRNA 1489, which was labeled with ${ }^{99 m} \mathrm{Tc}$, displayed a strong inhibitory effect in MCF-7 cell lines. The radiochemical purity of [ $\left.{ }^{99 \mathrm{~m}} \mathrm{Tc}\right] \mathrm{HYNIC}$-siRNA 1489 was stable at different temperatures in PBS and bovine serum. The T/M ratio of mice injected with [ $\left.{ }^{99 \mathrm{~m}} \mathrm{Tc}\right] \mathrm{HYNIC}$-siRNA 1489 was higher than that of those injected with the negative control, [99m Tc]HYNIC-NC siRNA. The percentage injected dose per $\mathrm{g}(\% \mathrm{ID} / \mathrm{g})$ of the tumors injected with ${ }^{99 \mathrm{~m}} \mathrm{Tc}$-HYNIC-siRNA 1489 was greater than that of the control group.

\section{Conclusions}

The [ $\left.{ }^{99 \mathrm{~m}} \mathrm{Tc}\right] \mathrm{HYNIC}$-siRNA 1489 was taken up by the tumor, which had a high level of MDM2. The probe exhibited a sufficient retention time in the tumor. It might afford an effective strategy for evaluating MDM2 expression and achieving earlier diagnosis in breast cancer.

\section{Background}

Breast cancer is the most common tumor in women [1]. It is well-known that mouse double minute 2 (MDM2), a ubiquitin ligase, can bind p53 and inhibit p53 transactivation of downstream genes [2]. In addition, MDM2 can ubiquitinate p53 and promote its proteasomal degradation [3-5]. As an oncogene, MDM2 is related to numerous human carcinoma, including breast cancer, glioma and prostate cancer [68]. MDM2 is able to mediate the Notch pathway by downregulating MOF in breast and liver cancer [6-8]. MDM2 is an E3 ligase that mediates SIRT6 degradation, and the interaction between MDM2 and SIRT6 is dependent on AKT1-mediated SIRT6 phosphorylation at Ser338 [10]. Moreover, many studies have shown 
that MDM2 overexpression is associated with breast cancer that have invasive potential and resistance to chemotherapy [10]. So MDM2 should be considered a promising target for breast carcinoma diagnosis and therapy.

Molecular imaging is a noninvasive method for diagnosing and imaging disease. With the development of molecular imaging technology, many imaging agents have been used in medicine. Small interfering RNA (siRNA), composed of a double strand of RNA, is responsible for RNA interference pathway (RNAi)based gene silencing. It is incorporated into RNA-induced silencing complex (RISC) and then Argonaute-2 cleaves the sense strand after siRNA is generated via dicer processing of a long double-stranded RNA or a synthetic siRNA is delivered into the cytoplasm [13]. But siRNAs have some inherent characteristics, such as off-target effects and biological instability, which need to be addressed before they can be incorporated in clinical applications. Chemical modifications of siRNAs have been shown to improve their inherent properties. For example, representative backbone modifications of siRNA include phosphorothioate (PS), ribose 2'-OH, 2'-O-methyl (2'-OMe) modifications. We decided to choose a 2'-OMe modification of the purines based on the following reasons. First, this modification site is the most attractive as it does not need to be recognized to target the mRNA cleavage process via the RNA induced silencing complex (RISC) [14]. Second, 2'-OMe modification increases the resistance of RNA to nucleic acid enzymes and its thermal stability $\left(T_{m}\right)$ increases $0.5-0.7^{\circ} \mathrm{C}$ per modification [14]. Third, modification of purine sites does not affect the silencing efficiency of siRNA.

In the present investigation, we used a chemically modified siRNA radiolabeled with ${ }^{99 \mathrm{~m}} \mathrm{Tc}$ to assess MDM2 expression directly via a visual method. The properties of [ $\left.{ }^{99 \mathrm{~m}} \mathrm{Tc}\right] \mathrm{HYNIC}$-siRNA were assessed in cell experiments. Furthermore, MDM2 imaging was used to assess MDM2 expression in breast cancer xenografts in vivo.

\section{Methods}

\subsection{The siRNA Design.}

Three different small interfering RNAs (siRNAs) against MDM2 were designed, and the sequences are listed as follows: MDM2 475 sense, 5'-GGCCAGUAUAUUAUGACUAd(TT)-3', antisense, 3'-

UAGUCAUAAUAUACUGGCCd(TT)-5'; MDM2 912 sense, 5'-GGAGAUAUGUUGUGAAAGAd(TT)-3', antisense, 3'-UCUUUCACAACAUAUCUCCd(TT)-5'; MDM2 1489 sense, 5'-CAGCCAUCAACUUCUAGUAd(TT)-3', antisense, 3'-UACUAGAAGUUGAUGGCUGd(TT)-5'. All siRNAs were modified with 2'-OMe by Genepharma Corp. (Shanghai, China). A primary amine was added at the 5 ' end of the antisense RNA. The amine provided a coupling site for HYNIC, which is important for radionuclide labeling. Quantitative real-time PCR (qRT-PCR) and western blots were used to select the optimal siRNA for inhibiting MDM2.

\subsection{The siRNA Radiolabeling and Characteristics.}


The siRNA $(5 \mu \mathrm{g} / \mu \mathrm{L})$ was diluted in $25 \mathrm{mM}$ ammonium acid carbonate buffer $(\mathrm{pH}=8.5)$. HYNIC (GL Biochem, Shanghai, China) was dissolved in dimethylformamide $(10 \mathrm{mg} / \mathrm{mL})$. Then siRNA was added in the proportions 20:1 (HYNIC:siRNA). The compounds reacted for $1 \mathrm{~h}$ at room temperature. The mixture was purified with a Sep-Pak C18 column (Waters, USA). The C18 column was activated by $20 \mathrm{~mL}$ of acetonitrile and washed with $20 \mathrm{~mL}$ deionized water. The siRNA and HYNIC mixture was diluted to $1 \mathrm{~mL}$ with deionized water and then loaded on the Sep-Pak C18 column, which was rinsed once with $10 \mathrm{~mL}$ $25 \mathrm{mM}$ ammonium bicarbonate ( $\mathrm{pH}=8.5)$, once with $10 \mathrm{~mL} 25 \mathrm{mM}$ ammonium bicarbonate $/ 5 \%$ acetonitrile, and twice with $10 \mathrm{~mL} 5 \%$ acetonitrile, and then siRNA was eluted with $1 \mathrm{~mL} 30 \%$ acetonitrile four times. The HYNIC-siRNA solution was collected in fractions of 8 drops/vial, HYNIC-siRNA was detected at $260 \mathrm{~nm}$, and vials with the highest concentrations of HYNIC-siRNA were combined. Then the product was dried by rotary evaporation for $6 \mathrm{~h}$, and the HYNIC-siRNA was stored at $-80^{\circ} \mathrm{C}$.

HYNIC-siRNA solution was prepared and tricine and EDDA were used as co-ligands. Ten $\mu \mathrm{g}$ HYNIC-siRNA were dissolved in $20 \mu \mathrm{L} 25 \mathrm{mM}$ ammonium acid carbonate $(\mathrm{pH}=8.5)$. Tricine $(50 \mu \mathrm{L}, 5.6 \mathrm{mM})$ and EDDA $(50 \mu \mathrm{L}, 5.6 \mathrm{mM})$ was added to the HYNIC-siRNA solution. Then, $10-20 \mu \mathrm{L}^{99 \mathrm{~m}} \mathrm{TcO}_{4}{ }^{-}$solution $(74-$ $185 \mathrm{MBq}$; China Isotope \& Radiation Corporation, Beijing, China) were diluted with $5.5 \mu \mathrm{L}$ of $\mathrm{SnCl}_{2} \cdot 2 \mathrm{H}_{2} \mathrm{O}$ (4.4 $\mathrm{mM}$ in $0.1 \mathrm{M} \mathrm{HCl}$ ) and mixed with the HYNIC-siRNA solution. After $1 \mathrm{~h}$, the mixture was purified using

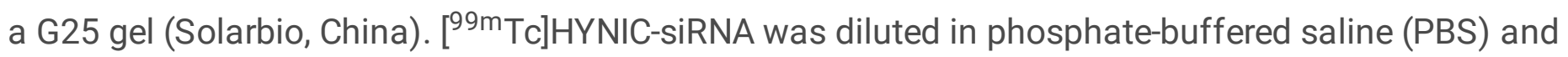
bovine serum albumin $(0.01 \mu \mathrm{g} / \mu \mathrm{L})$ and then incubated at room temperature and $37^{\circ} \mathrm{C}$ for $6 \mathrm{~h}$. Its stability in vitro was evaluated by its radiochemical purity at different times.

\subsection{Cell Lines and Cell Culture.}

Human breast cancer cell lines MCF-7 and MDA-MB-231 were purchased from the Chinese Academy of Sciences Shanghai Cell Bank. The cells were cultured in RPMI 1640 complete medium (Gibco, USA) at $37^{\circ} \mathrm{C}$ in an incubator containing $5 \% \mathrm{CO}_{2}$. The complete medium was comprised of $10 \%$ fetal bovine serum (FBS), penicillin $(100 \mathrm{U} / \mathrm{mL})$ and streptomycin $(100 \mu \mathrm{g} / \mathrm{mL})$.

\subsection{Transfection of [ ${ }^{99 m}$ Tc]HYNIC-siRNA.}

MCF-7 cells were trypsinized and transferred to 6-well plates at a concentration of $1 \times 10^{6} \mathrm{cells} / \mathrm{well}$. Then the RPMI 1640 medium was added to each well. After the cells reached $70 \%$ confluency, the medium was replaced by opti-MEM (Gibco, USA). Two $\mu \mathrm{g}$ siRNA1489, control siRNA, and/or [ ${ }^{99 \mathrm{~m}} \mathrm{Tc}$ ]HYNIC-siRNA1489 were separately dissolved in $200 \mu \mathrm{L}$ opti-MEM. Eight $\mu \mathrm{L}$ of Lipofectamine 2000 (Invitrogen, USA) solution were added to each of three 200- $\mu \mathrm{L}$ aliquots of opti-MEM. Then, the Lipofectamine 2000/opti-MEM mixture was added to the siRNA1489, control siRNA, and [99m Tc]HYNIC-siRNA1489 mixtures and all were incubated for $20 \mathrm{~min}$ at room temperature. In the final solutions, the siRNA concentration reached $0.01 \mu \mathrm{g} / \mu \mathrm{L}$. Then the liposome-encapsulated control siRNA, liposome-encapsulated siRNA1489, and liposome-encapsulated [ $\left.{ }^{99 \mathrm{~m}} \mathrm{TC}\right] \mathrm{HYNIC}$-siRNA1489 were individually added to MCF-7 cells and cultured in 
an incubator $\left(37^{\circ} \mathrm{C}\right.$ and $\left.5 \% \mathrm{CO}_{2}\right)$ for $6 \mathrm{~h}$. The opti-MEM was removed and complete medium was added. After $24 \mathrm{~h}$, the MCF-7 cells were collected and used for qRT-PCR and western blotting.

\subsection{The $q R T-P C R$.}

Total RNA was extracted using a RNAprep Pure Cell/Bacteria Kit (Tiangen, China) according to the manufacturer's protocol. cDNAs were synthesized from total RNA $(1 \mu \mathrm{g})$ using random primers with the RevertAid First Strand cDNA Synthesis Kit (Thermo Scientific, USA). The qRT-PCR was performed with the MDM2 and internal reference GAPDH primer set (MDM2 forward, 5'-CCTTAGCTGACTATTGGAAATGCA-3, reverse, 5'-CGAAGGGCCCAACATCTGT-'3; GAPDH forward, 5'-CACCCACTCCTCCACCTTTGA-3', reverse, 5'ACCACCCTGTTGCTGTAGCCA-3') under the following PCR conditions: pre-denaturation at $95^{\circ} \mathrm{C}$ for $60 \mathrm{~s}$, denaturation at $95^{\circ} \mathrm{C}$ for $15 \mathrm{~s}$, and extension at $60^{\circ} \mathrm{C}$ for $60 \mathrm{~s}$, for 40 cycles.

\subsection{Western Blots.}

MCF-7 cells were lysed in RIPA buffer with PMSF (100:1) for 30 min on ice, then centrifuged at 12,000 9 at $4{ }^{\circ} \mathrm{C}$ for $15 \mathrm{~min}$. The supernatant was collected and mixed with SDS-PAGE buffer then denatured, and the total protein was measured using a BCA Protein Assay Kit (Tiangen, China). Equal amounts of protein were separated by $10 \%$ SDS-polyacrylamide gels and transferred onto polyvinylidene difluoride membranes (Millipore, USA). Membranes were blocked using $5 \%$ non-fat milk in TBST for $1 \mathrm{~h}$ at $37^{\circ} \mathrm{C}$, followed by overnight incubation with anti-MDM2 (ab178938; Abcam, USA) and anti- $\beta$-actin (20536-1-AP; Proteintech, China) antibodies at $4{ }^{\circ} \mathrm{C}$. Unbound antibody was removed by three 10-min washes in TBST solution. Membranes were then incubated for $1 \mathrm{~h}$ at room temperature with secondary antibody (ZB-2301; Zhong Shan Gold Bridge, China) conjugated with HRP, followed by three 10-min washes with TBST buffer. The blots were visualized with ECL reagent (Advansta, USA) and a Tanon-5200 Chemiluminescent Imaging System (TanonScience \& Technology, China).

\subsection{Animal Models.}

Female NU/NU nude mice (aged 6-8 weeks, body weight 18-22 g) were purchased from Peking Vital River Experimental Animal Co. Ltd. All protocols involving animals were performed under the supervision of the Institutional Animal Care and Use Committee of Harbin Medical University. Mice were randomly divided into two groups. A MCF-7 cell suspension $\left(5 \times 10^{6}\right.$ cells) was directly injected into the right hind limb of each mouse. The mice were maintained in a standard environment with sufficient food and drinking water. The imaging experiments were carried out when the tumor reached $500 \mathrm{~mm}^{3}$ (tumor volume $[\mathrm{mm}]^{3}=$ length $[\mathrm{mm}] \times$ width $[\mathrm{mm}]^{2} \times 0.5$ )

\subsection{Molecular Imaging and Biodistribution Assay.}


TurboFect (Invitrogen, USA)-encapsulated [ $\left.{ }^{99 \mathrm{~m}} \mathrm{Tc}\right] \mathrm{HYNIC}$-siRNA $1489(7.4 \mathrm{MBq})$ and [ $\left.{ }^{99 \mathrm{~m}} \mathrm{Tc}\right] \mathrm{HYNIC}$-control siRNA $(7.4 \mathrm{MBq})$ were separately injected into the two groups of mice $(n=6)$ via the tail vein. SPECT with a low energy, high resolution, pinhole collimator was prepared. At $1 \mathrm{~h}, 4 \mathrm{~h}$, and $10 \mathrm{~h}$ after injection, all mice were scanned with SPECT (Discovery 670; GE Healthcare). All mice were subjected to abdominal anesthesia with $1 \%$ pentasorbital sodium $(0.04 \mathrm{~mL} / 10 \mathrm{~g})$. Counts of images reaching 100 were stored.

The matrix was $256 \times 256$ and the zoom factor was 2.0. The regions of interest of each tumor were drawn and counted. Radiocounting of equal areas of muscle on the opposite limb were recorded as a control. Finally, the tumor-to-muscle (T/M) ratio was calculated.

Thirty-six NU/NU nude mice with MCF-7 xenografts were randomly divided into two groups of 18. A biodistribution study was performed after tail vein injection of TurboFect-encapsulated [ $\left.{ }^{99 \mathrm{~m}} \mathrm{Tc}\right] \mathrm{HYNIC}$ siRNA3 (7.4 MBq) or [ $\left.{ }^{99 \mathrm{~m}} \mathrm{Tc}\right] \mathrm{HYNIC}$-control siRNA (7.4 MBq). At $1 \mathrm{~h}, 4 \mathrm{~h}$, and $6 \mathrm{~h}$ post injection, four mice from each group were sacrificed by inhalation of isoflurane followed by cervical dislocation. Major internal organs including the brain, lungs, liver, spleen, kidneys, stomach, intestines, muscle, thyroid and blood, together with the tumor, were collected and weighed, and the radioactivity was measured via a gamma counter. The radioactivities of tissues were represented by the percentage of injected dose per $\mathrm{g}$ of organ $(\% \mathrm{ID} / \mathrm{g})$. The mass ratio of the tumor to the contralateral muscle $(\mathrm{T} / \mathrm{M})$ was also calculated.

\subsection{Blocking assay}

Six NU/NU nude mice with MCF-7 xenografts were used in blocking assay. Non-labelled siRNA 1489 ( $1 \mathrm{mg} / \mathrm{kg}$ ) encapsulated with TurboFect was injected into MCF-7 xenografts for 3 hours before injecting imaging agent. Then repeat the imaging procedure, the radioactivities of tissues were represented by the percentage of injected dose per $\mathrm{g}$ of organ $(\% \mathrm{ID} / \mathrm{g})$.

2.10. Statistical Analysis. Each experiment was performed in triplicate with duplication for each sample tested. Statistical analysis was performed with SPSS 18.0. Data are expressed as the mean \pm SD. Statistical differences were analyzed via one-way analysis of variance. $P<0.05$ was considered statistically significant.

\section{Results}

\subsection{Expression of MDM2 in Breast Cancer Cell Lines.}

To choose suitable cell lines with high levels of MDM2 qRT-PCR and western blots were used to evaluate MDM2 expression in MCF-7 and MDA-MB-231 cells. The results showed that the relative expression levels of MCF-7 and MDA-MB-231 mRNAs were $1 \pm 0.14$ and $0.40 \pm 0.06(p<0.05, n=3)$, respectively (Fig. 1a). The protein levels of MCF-7 and MDA-MB-231 cells were $1 \pm 0.05$ and $0.35 \pm 0.15(p<0.05, n=3)$, respectively (Fig. 1b). This meant that MCF-7 had a high level of MDM2 and was suitable for the imaging experiment. 


\subsection{Inhibitory Effects of siRNA In Vitro.}

Three siRNA sequences were designed and their inhibitory effects were investigated to select the best one. The inhibitory effects of each siRNA were estimated according to the protein expression and mRNA content determined by western blots and quantitative real-time PCR (Fig. 1c and d). The results of transfection with the three siRNA sequences showed substantially lower MDM2 mRNA and protein levels than those of the negative control siRNA and blank control groups transfected with Opti-MEM $(p<0.05, n$ $=3$ ). There were no significance differences among the three siRNA sequences.

\subsection{In Vitro $99 m$}

Tc-HYNIC-siRNA Stability. The labeling efficiencies of [ $\left.{ }^{99 \mathrm{~m}} \mathrm{Tc}\right] \mathrm{HYNIC}$-siRNA1489 and [ ${ }^{99 \mathrm{~m}} \mathrm{Tc}$ ]HYNIC-control siRNA were $62.17 \pm 3.16 \%$ and $61.56 \pm 4.08 \%(p>0.05, n=4)$, respectively. The radiochemical purities of the probes were over $94 \%$ after purification. When the probes were tested at normal temperature $\left(37^{\circ} \mathrm{C}\right)$, the radiochemical purity did not significantly change $(n=3)$. With increasing incubation time, the probes were stable within $6 \mathrm{~h}$ and did not show significant degradation. Similarly, there was no difference between cultures in phosphate-buffered saline (PBS) and fetal bovine serum (FBS) (Fig. 2a). This indicated that the probes had relatively stable physicochemical properties.

\subsection{In Vitro Inhibitory Effect of siRNA1489 after Labeling with ${ }^{99 m}$ Tc.}

We tested the effect of [ $\left.{ }^{99 \mathrm{~m}} \mathrm{Tc}\right] \mathrm{HYNIC}$-siRNA1489 via qRT-PCR and western blots in MCF-7 cell lines. There was an obvious inhibiting effect of siRNA1489 unlabeled with ${ }^{99 \mathrm{~m}} \mathrm{Tc}$. We compared the results for siRNA1489 labeled with ${ }^{99 \mathrm{~m}} \mathrm{Tc}$ to unlabeled siRNA1489 and blank control. From our experiments, radiolabeling of siRNA1489 did not affect the RNAi effect (Fig. 2b and c). [ ${ }^{99 m}$ Tc]HYNIC-siRNA 1489 still inhibited the expression of MDM2. The relative expressions of MDM2 mRNA and protein were $0.34 \pm 0.06$ and $0.46 \pm 0.09(p<0.05, n=3)$, respectively (Fig. $2 b$ and $c)$. This indicated that siRNA conjugated with ${ }^{99 \mathrm{~m}} \mathrm{Tc}$ could be applied to in vitro experiments.

\subsection{MDM2 Molecular Imaging.}

Nude mice with xenografts of MCF-7 cell lines were used for molecular imaging. The tumors were observed by SPECT at $1 \mathrm{~h}, 4 \mathrm{~h}, 10 \mathrm{~h}$ after injection of [ $\left.{ }^{99 \mathrm{~m}} \mathrm{Tc}\right] \mathrm{HYNIC}$-siRNA 1489 or the negative control, [ $\left.{ }^{99 \mathrm{~m}} \mathrm{Tc}\right] \mathrm{HYNIC}-\mathrm{NC}$ siRNA. We detected a distinct difference between [ $\left.{ }^{99 \mathrm{~m}} \mathrm{Tc}\right] \mathrm{HYNIC}-\mathrm{siRNA} 1489$ and the negative control group as the T/M ratios were $3.079 \pm 0.57$ and $1.472 \pm 0.27(p<0.05, n=6)$ at $1 \mathrm{~h}$, respectively. The T/M ratios for [ $\left.{ }^{99 \mathrm{~m}} \mathrm{Tc}\right]$ HYNIC-siRNA 1489 and [ $\left.{ }^{99 \mathrm{~m}} \mathrm{Tc}\right]$ HYNIC-NC siRNA were $2.927 \pm 0.14$ and $1.272 \pm 0.11$ at $4 \mathrm{~h}$ (Fig. 3a). Furthermore, with the extension of time, the images of tumors in mice 
injected with $\left[{ }^{99 \mathrm{~m}} \mathrm{Tc}\right] \mathrm{HYNIC}$-siRNA 1489 were clearer than the negative control group injected with $\left[{ }^{99 \mathrm{~m}}\right.$ Tc]HYNIC-NC siRNA. At $10 \mathrm{~h}$, the T/M ratios reached a peak: $\left[{ }^{99 \mathrm{~m}} \mathrm{Tc}\right] \mathrm{HYNIC}$-siRNA 1489 was $3.465 \pm$ 0.43 and $\left[{ }^{99 \mathrm{~m}} \mathrm{TC}\right] \mathrm{HYNIC}-\mathrm{NC}$ siRNA was $1.804 \pm 0.11$ (Fig. 3a). In the NC group, the imaging of mouse tumors was not observed at every time point. The blocking experiment was used to assess the specificity of [ $\left.{ }^{99 \mathrm{~m}} \mathrm{Tc}\right]$ HYNIC-siRNA 1489 (Fig. 3c). The accumulation of [ $\left.{ }^{99 \mathrm{~m}} \mathrm{Tc}\right]$ HYNIC-siRNA 1489 pre-treated with siRNA 1489 was lower than without siRNA 1489 in MCF-7 xenografts. Our results showed that the MDM2 molecular probe could reveal MDM2 transcription levels in vivo.

\subsection{Biodistribution Studies.}

After the imaging experiments, we measured the biodistributions of the probes in the nude mice with a

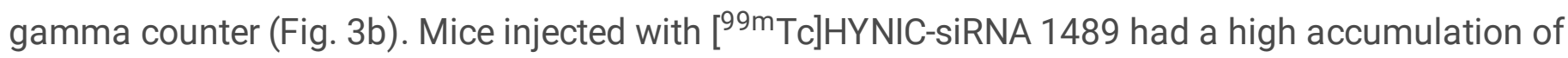
nuclide in the tumor at $1 \mathrm{~h}$ and $4 \mathrm{~h}(4.28 \pm 0.47 \% \mathrm{ID} / \mathrm{g}$ and $5.93 \pm 0.86 \% \mathrm{ID} / \mathrm{g}, \mathrm{n}=6)$, respectively. The accumulation of $\left[{ }^{99 m} \mathrm{Tc}\right] \mathrm{HYNIC}$-siRNA 1489 rose to a peak at $6 \mathrm{~h}(6.42 \pm 0.66 \% \mathrm{ID} / \mathrm{g})$. Mice injected with [ $\left.{ }^{99 \mathrm{~m}} \mathrm{TC}\right] \mathrm{HYNIC}-\mathrm{NC}$ siRNA did not display an obvious accumulation of nuclide in the tumor at the different time points $(2.24 \pm 0.39 \% \mathrm{ID} / \mathrm{g}, 1.96 \pm 0.28 \% \mathrm{ID} / \mathrm{g}$ and $1.66 \pm 0.17 \% \mathrm{ID} / \mathrm{g})$. Based on these data, we thought $\left[{ }^{99 \mathrm{~m}} \mathrm{Tc}\right] \mathrm{HYNIC}$-siRNA 1489 would be taken up by the tumor and have a long retention time. There was a high accumulation in the liver $(14.92 \pm 1.46 \% \mathrm{ID} / \mathrm{g}$ in the NC group and $14.48 \pm 0.99 \% \mathrm{ID} / \mathrm{g}$ in the siRNA 1489 group) and kidney (13.34 $\pm 1.22 \% \mathrm{ID} / \mathrm{g}$ in the NC group and $13.65 \pm 1.05 \% \mathrm{ID} / \mathrm{g}$ in the siRNA 1489 group) in both groups at $1 \mathrm{~h}$. Then the radioactivities in the liver and kidney decreased over time. This signified that the molecular probe was cleared via the urinary system and the liver.

\section{Discussion}

In recent years, molecular biology technology has developed rapidly. Imaging used for the diagnosis of disease is no longer limited to anatomical imaging. Researchers have aimed to use functional imaging and metabolic imaging, and gene imaging has become the focus. Gene imaging reveals changes in cellular physiological processes at the genetic level and it has a high potential to aid early and accurate diagnosis. In gene imaging, RNA interference (RNAi) technology has become a hot research topic because siRNA can effectively combine with target gene mRNA. The siRNA has a high specificity and efficiency. In the past few decades, the therapeutic potential of siRNA has been confirmed in diseases such as viral infections and cancers [16-18].

The key to molecular imaging is to synthesize molecular probes that target the tumor, which means these molecular probes must have high specificity. It also requires the target tissue to overexpress certain molecules such as proteins or nucleic acids. In this study, MDM2 was selected as the target gene because it plays an important role in different tumor cells [16-18]. MDM2 is the major downstream regulator gene of p53. It can form a negative feedback loop with p53 leading to its degradation via ubiquitination and proteasomes. The mutation of $p 53$ in different cancers will cause immortalization of cells, which is the first step in tumorigenesis [22]. However, the expression of p53 in cancer cells is too low to be detected in 
vivo by noninvasive methods. In contrast, the high expression levels of MDM2 in cancer cells provide a new approach to diagnosis and treatment. As a negative regulator, the content of MDM2 could reflect the content of p53 indirectly. Park found that different types of breast cancers that express high levels of MDM2 in both the nucleus and cytoplasm were more malignant [23]. Therefore, the early detection of MDM2 is vitally important for the diagnosis and treatment of tumors. In our research we selected two kinds of breast cancer cells to determine which expresses higher amounts of MDM2. The PCR results proved that the MCF-7 cells expressed MDM2 at higher levels. We used MCF-7 cells to show which siRNA combined with the MDM2 gene. Finally, the results of PCR and western blots revealed that siRNA1489 was the best choice, so it was used in further experiments.

We used TurboFect as a carrier in the in vivo experiments. It is lipophilic and is often used for nonviral transfection. TurboFect could combine with siRNA through electrostatic interactions, and TurboFectsiRNA was adsorbed to the electronegative cytomembrane and transferred into the cells. Then the siRNA and DNA could bind and play a role. The siRNA probe could be carried into the cells by lipo2000 in vitro, but the way it penetrated the cytomembrane in vivo and its intake rate were the keys to the experiment. And these factors are related to the transcription and translation of the target gene. In general, cells can take in large molecules via endocytosis, and small molecules can enter cells through specific channels or transporters. But there is no specific channel for siRNA and it is easily excreted by the reticuloendothelial system. Hence, the targeting efficiency may decrease in vivo, so we attempted to increase the probe uptake by using TurboFect for in vivo experiments. In order to solve the problem of rapid degradation and excretion of siRNA in vivo, double strand siRNA was selected in these experiments. Because the half-life of double-chain siRNA is longer than that of single-chain siRNA, the inhibiting efficiency of double-chains siRNA is significantly higher than that of single-chain siRNA [24]. Furthermore, we used a 2'OMe modification for the sense strand of siRNA because the 2'OMe modification did not affect RNA silencing and splicing. It is one of the compatible modification methods, as it not only increased the resistance of siRNA to nucleases but also enhanced the interference effect of siRNA and its thermal stability [25]. Another method that enhances resistance to nucleases is the modification of $\mathrm{U}$ and $\mathrm{C}$ bases with fluorine. In order to enhance the binding of the siRNA to the target gene, we added two free dTT bases on the 3'end [26]. The amino modification on the 5'end was used to couple with HYNIC. Finally, HYNIC was

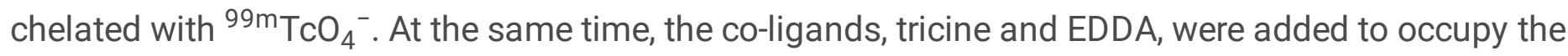
void position of ${ }^{99} \mathrm{~m}_{\mathrm{TcO}_{4}}{ }^{-}$. The PCR and western blot results showed that [ ${ }^{99 \mathrm{~m}} \mathrm{Tc}$ ]HYNIC-siRNA1489 significantly inhibited the expression of mRNA and MDM2 protein after transfection of the MCF-7 cells. The stability of the siRNA-MDM2 probe was validated in PBS and serum, which provided a basis for imaging of animal tumors.

In addition to the characteristics of the molecular probe, radiochemical purity and labeling efficiency were also important. If the radiochemical purity of the probe was low, excessive free ${ }^{99 \mathrm{~m}} \mathrm{TcO}_{4}{ }^{-}$will be absorbed by the thyroid, which would interfere with tumor imaging. Similarly, if the labeling efficiency was low, the molecular probe that was injected into the nude mice would be taken up at lower levels. All of these 
factors will affect the imaging. So we used chromatography to determine the radiochemical purity and labeling efficiency after purifying the molecular probe, and the results were satisfactory.

In these experiments, the [ $\left.{ }^{99 \mathrm{~m}} \mathrm{Tc}\right] \mathrm{HYNIC}$-siRNA1489 inhibition rate of MDM2 mRNA in vitro reached about $70 \%$. The western blot results showed that the inhibition of MDM2 protein was also substantial. This relied on the combination of siRNA with MDM2 mRNA in vitro. To detect the specificity of the probe, we divided the nude mice into two groups, and [ $\left.{ }^{99 \mathrm{~m}} \mathrm{Tc}\right] \mathrm{HYNIC}$-siRNA1489 and [99m Tc]HYNIC-control siRNA were injected into the mice in in vivo experiments. Tumor images of the control group injected with $\left[{ }^{99 \mathrm{~m}} \mathrm{Tc}\right] \mathrm{HYNIC}$-control siRNA were not detected by SPECT. Furthermore, the tumors of the probe group injected with [ $\left.{ }^{99 \mathrm{~m}} \mathrm{Tc}\right] \mathrm{HYNIC}$-siRNA 1489 were clearly delineated. The T/M ratios of the tumors in the molecular probe group were higher than those in the control group. With time, the images of the tumors became clearer. This indicated that the probe had sufficient retention time in the tumor, and siRNA could bind to the target genes specifically and be available for gene targeted imaging.

\section{Conclusion}

$\left[{ }^{99 \mathrm{~m}} \mathrm{Tc}\right] \mathrm{HYNIC}$-siRNA accumulated in the tumors and had a sufficiently long retention time to allow imaging. The SPECT imaging reflected the MDM2 expression levels indirectly. [ ${ }^{99 \mathrm{~m}} \mathrm{Tc}$ ]HYNIC-siRNA might be an effective method for assessing the MDM2 expression via in vivo imaging.

\section{Declarations}

\section{Ethics approval and consent to participate}

This project was approved by the Medical Ethics Expert Committee of Harbin Medical University. All procedures performed in studies involving animals were in accordance with the ethical standards of the institutional research committee for animals.

\section{Consent for publication}

Not applicable.

\section{Availability of data and materials}

The full datas used and analyzed during the current study are available on reasonable request from the corresponding authors.

\section{Competing interests}

The authors declare that they have no conflicts of interest. 


\section{Funding}

This research was supported by the National Natural Science Foundation of China [grant numbers $81671714,81771864]$.The funders have a role in the design of the research, and writing the manuscript.

\section{Authors' contributions}

$\mathrm{XW}, \mathrm{PX}, \mathrm{PF}$, and $\mathrm{CZ}$ designed research; XW, PX, YJ, SL, and YG performed the experiment. XW, PX, YJ, SL, and $Y G$ analyzed the data; $X W, P X, P F$, and $C Z$ wrote the manuscript. The authors read and approved the final manuscript.

\section{Acknowledgements}

Not applicable.

\section{References}

1. DeSantis CE, Ma J, Gaudet MM, Newman LA, Miller KD, Goding SA, et al. Breast cancer statistics, 2019. CA Cancer J Clin. 2019;69:438-51.

2. Shvarts A, Steegenga WT, Riteco N, van Laar T, Dekker P, Bazuine M, et al. MDMX: a novel p53binding protein with some functional properties of MDM2. EMBO J. 1996;15:5349-57.

3. Kubbutat MH, Jones SN, Vousden KH. Regulation of p53 stability by Mdm2. Nature. 1997;387:299303.

4. Haupt Y, Maya R, Kazaz A, Oren M. Mdm2 promotes the rapid degradation of p53. Nature. 1997;387:296-9.

5. Honda R, Tanaka H, Yasuda H. Oncoprotein MDM2 is a ubiquitin ligase E3 for tumor suppressor p53. FEBS Lett. 1997;420:25-7.

6. Fan Y, Ma K, Jing J, Wang C, Hu Y, Shi Y, et al. Recombinant dual-target MDM2/MDMX inhibitor reverses doxorubicin resistance through activation of the TAB1/TAK1/p38 MAPK pathway in wildtype p53 multidrug-resistant breast cancer cells. J Cancer. 2020;11:25-40.

7. Feng FY, Zhang Y, Kothari V, Evans JR, Jackson WC, Chen W, et al. MDM2 inhibition sensitizes prostate cancer cells to androgen ablation and radiotherapy in a p53-dependent manner. Neoplasia. 2016;18:213-22.

8. Tong $\mathrm{H}$, Zhao K, Zhang J, Zhu J, Xiao J. YB-1 modulates the drug resistance of glioma cells by activation of MDM2/p53 pathway. Drug Des Devel Ther. 2019;13:317-26.

9. Liu Y, Xing ZB, Wang SQ, Chen S, Liu YK, Li YH, et al. MDM2-MOF-H4K16ac axis contributes to tumorigenesis induced by Notch. FEBS J. 2014;281:3315-24. 
10. Thirumurthi U, Shen J, Xia W, LaBaff AM, Wei Y, Li CW, et al. MDM2-mediated degradation of SIRT6 phosphorylated by AKT1 promotes tumorigenesis and trastuzumab resistance in breast cancer. Sci Signal. 2014;7:a71.

11. Fan Y, Li M, Ma K, Hu Y, Jing J, Shi Y, et al. Dual-target MDM2/MDMX inhibitor increases the sensitization of doxorubicin and inhibits migration and invasion abilities of triple-negative breast cancer cells through activation of TAB1/TAK1/p38 MAPK pathway. Cancer Biol Ther. 2019;20:61732.

12. Lu J, McEachern D, Li S, Ellis MJ, Wang S. Reactivation of p53 by MDM2 inhibitor Ml-77301 for the treatment of endocrine-resistant breast cancer. Mol Cancer Ther. 2016;15:2887-93.

13. Ku SH, Jo SD, Lee YK, Kim K, Kim SH. Chemical and structural modifications of RNAi therapeutics. Adv Drug Deliv Rev. 2016;104:16-28.

14. Chiu YL, Rana TM. siRNA function in RNAi: a chemical modification analysis. RNA. 2003;9:1034-48.

15. Choung S, Kim YJ, Kim S, Park HO, Choi YC. Chemical modification of siRNAs to improve serum stability without loss of efficacy. Biochem Biophys Res Commun. 2006;342:919-27.

16. Muller K, Klein PM, Heissig P, Roidl A, Wagner E. EGF receptor targeted lipo-oligocation polyplexes for antitumoral siRNA and miRNA delivery. Nanotechnology. 2016;27:464001.

17. Zhang M, Wang $X$, Han MK, Collins JF, Merlin D. Oral administration of ginger-derived nanolipids loaded with siRNA as a novel approach for efficient siRNA drug delivery to treat ulcerative colitis. Nanomedicine (Lond). 2017;12:1927-43.

18. Jose A, Labala S, Venuganti VV. Co-delivery of curcumin and STAT3 siRNA using deformable cationic liposomes to treat skin cancer. J Drug Target. 2017;25:330-41.

19. Li W, Wang SS, Deng J, Tang JX. Association of p73 gene G4C14-A4T14 polymorphism and MDM2 gene SNP309 with non-small cell lung cancer risk in a Chinese population. Oncol Lett. 2017;14:1817-22.

20. Davoodi P, Srinivasan MP, Wang CH. Effective co-delivery of nutlin-3a and p53 genes via core-shell microparticles for disruption of MDM2-p53 interaction and reactivation of p53 in hepatocellular carcinoma. J Mater Chem B. 2017;5:5816-34.

21. Chaudhary R, Muys BR, Grammatikakis I, De S, Abdelmohsen K, Li XL, et al. A circular RNA from the MDM2 locus controls cell cycle progression by suppressing p53 levels. Molecular and Cellular Biology. 2020;40.

22. Kaul SC, Aida S, Yaguchi T, Kaur K, Wadhwa R. Activation of wild type p53 function by its Mortalinbinding, cytoplasmically localizing carboxyl terminus peptides. J Biol Chem. 2005;280:39373-9.

23. Park HS, Park JM, Park S, Cho J, Kim SI, Park BW. Subcellular localization of Mdm2 expression and prognosis of breast cancer. Int J Clin Oncol. 2014;19:842-51.

24. Liao H, Wang JH. Biomembrane-permeable and ribonuclease-resistant siRNA with enhanced activity. Oligonucleotides. 2005;15:196-205.

25. Chiu YL, Rana TM. siRNA function in RNAi: a chemical modification analysis. RNA. 2003;9:1034-48. 

stability without loss of efficacy. Biochem Biophys Res Commun. 2006;342:919-27.

\section{Figures}

a

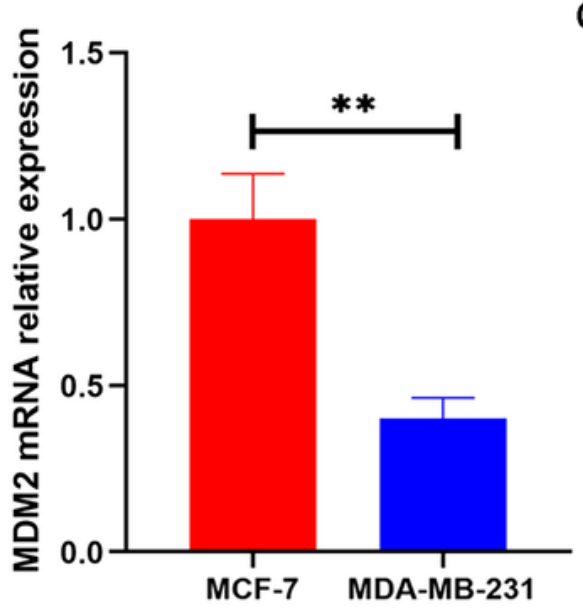

b

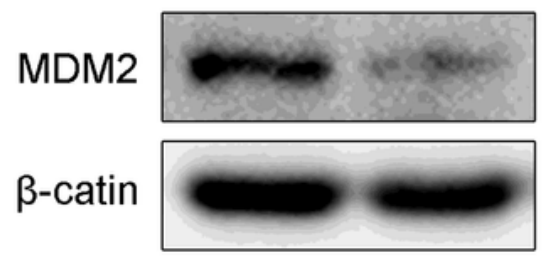

MCF-7 MDA-MB-231

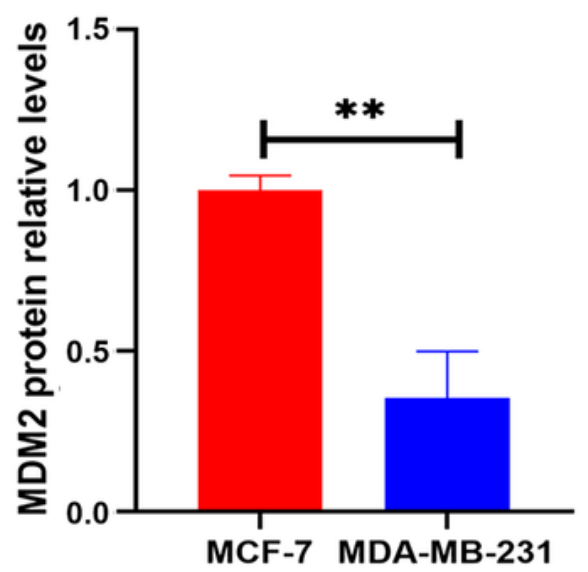

$\mathrm{C}$

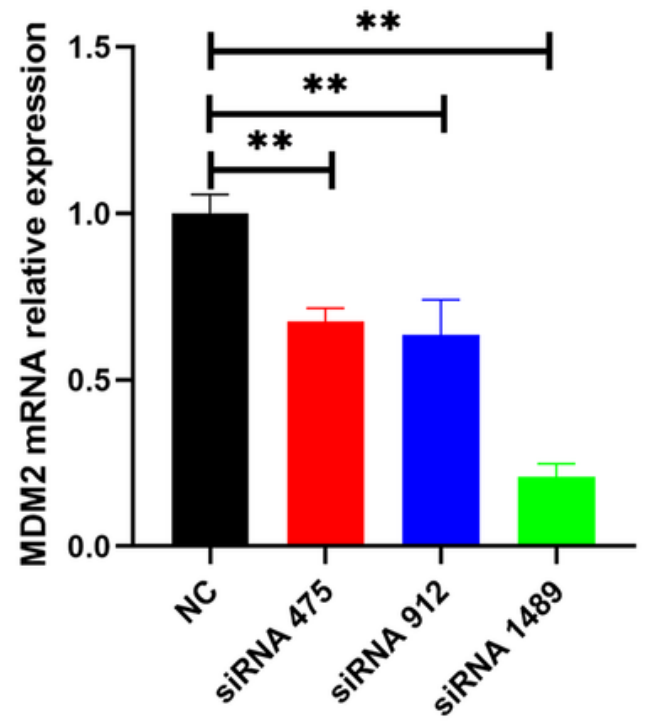

d
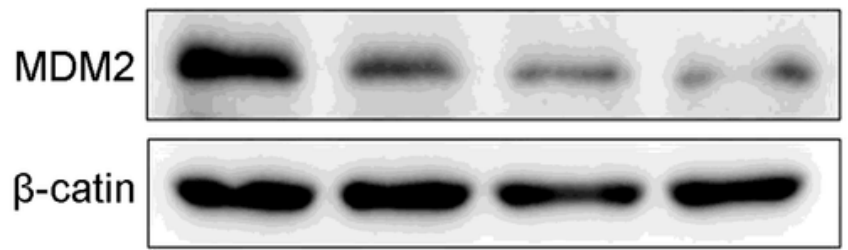

a
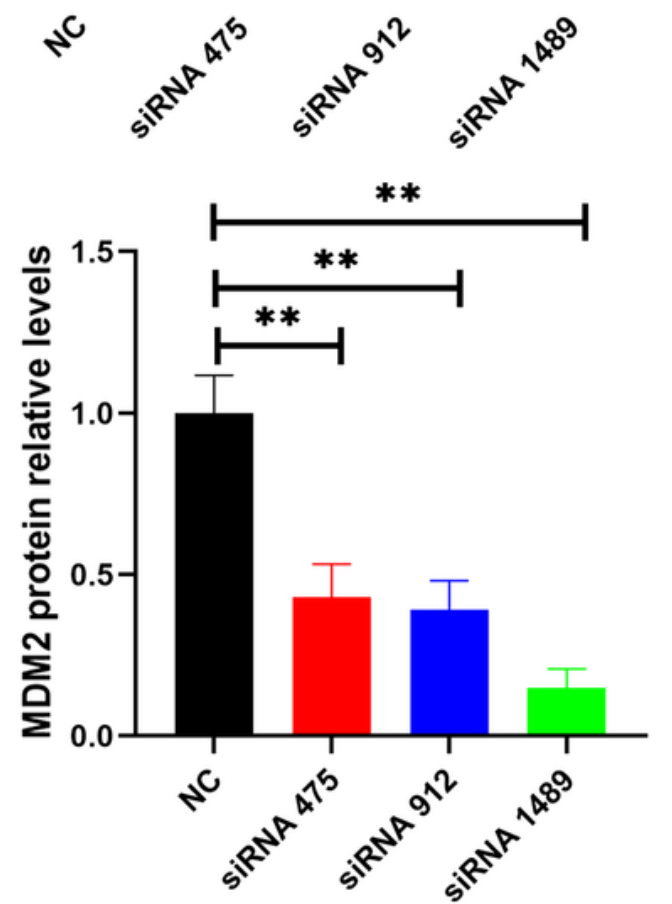

Figure 1 
MDM2 expression in breast cancer cell lines and the inhibition efficiency of siRNA. (a) MDM2 mRNA relative expression. (b) MDM2 protein relative expression. (c) MDM2 mRNA relative expression after transfecting siRNA in MCF-7 cells. (d) MDM2 protein relative expression after transfecting siRNA in MCF7 cells. Data are presented as the mean $\pm S D$ based on three independent experiments. ${ }^{\star} P<0.05 ;{ }^{*} \mathrm{P}<$ 0.01 versus the $\mathrm{NC}$ group.
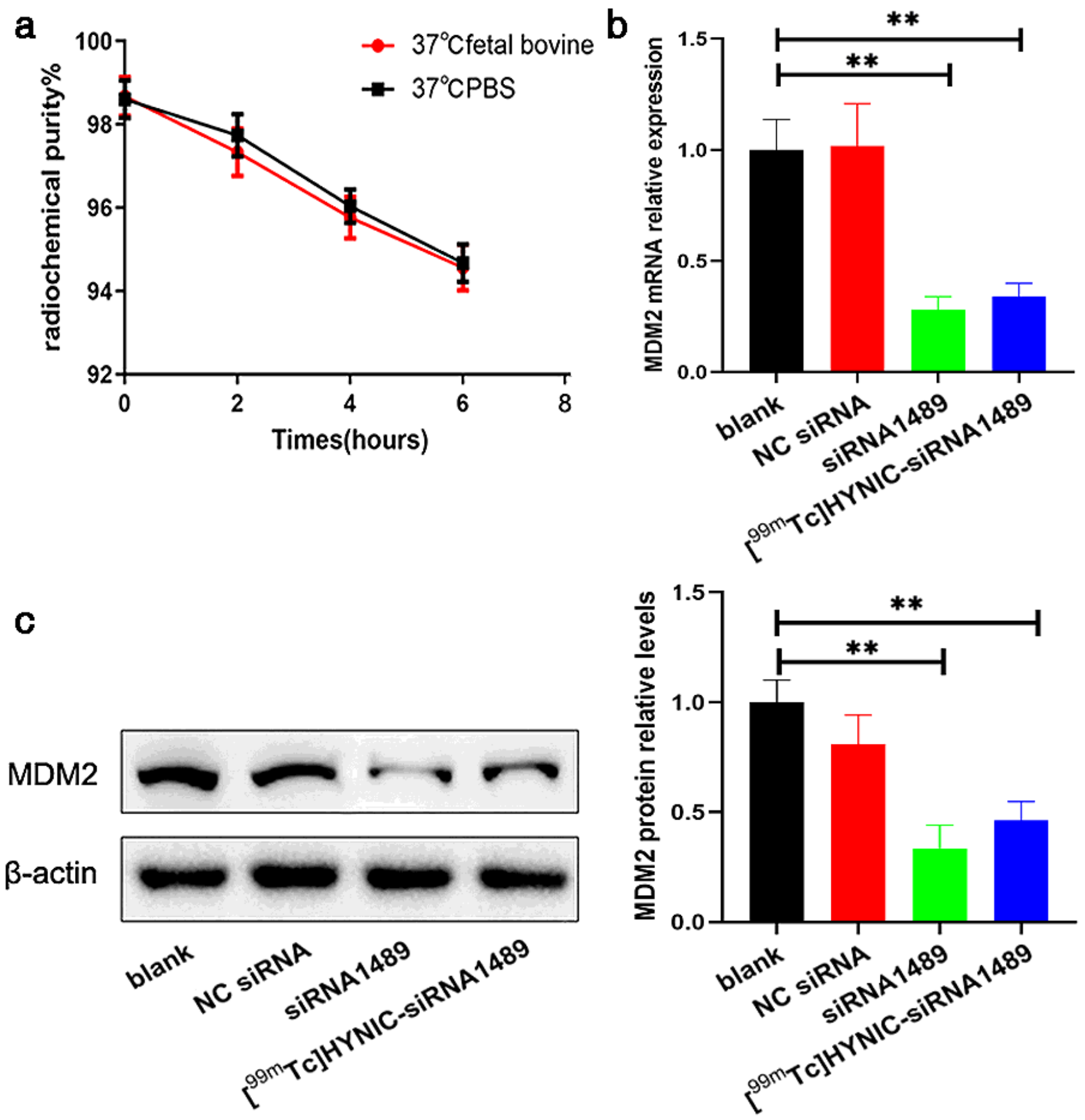

Figure 2 
Stability and biological activity of [99mTc]HYNIC-siRNA in vitro. (a) Radiochemical purity of [99mTc]HYNIC-siRNA incubated in PBS and bovine serum at $37^{\circ} \mathrm{C}$. (b) MDM2 mRNA relative expression after transfection with NC siRNA, siRNA 1489and [99mTc]HYNIC-siRNA 1489 measured by qRT-PCR. (c) MDM2 protein relative expression after transfection with NC siRNA, siRNA 1489 and [99mTc]HYNICsiRNA 1489 measured by western blots. Data are presented as the mean $\pm S D$ based on three independent experiments. ${ }^{*} \mathrm{P}<0.05 ;{ }^{*} \mathrm{P}<0.01$ versus the NC group.

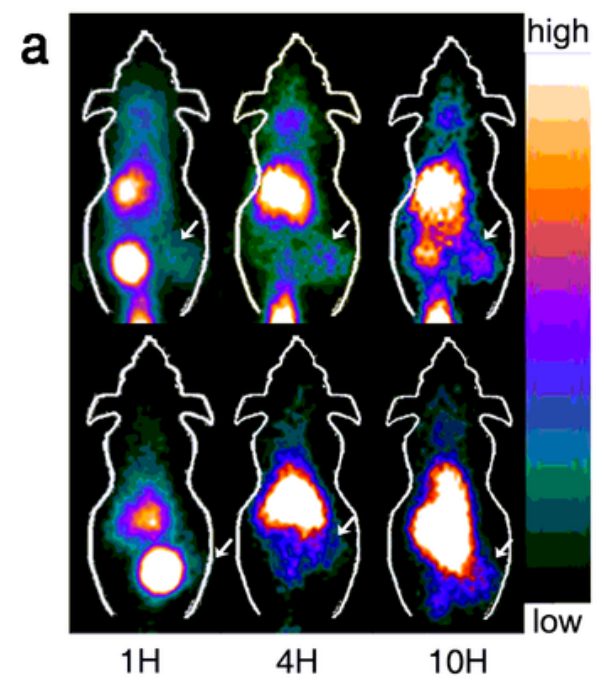

b

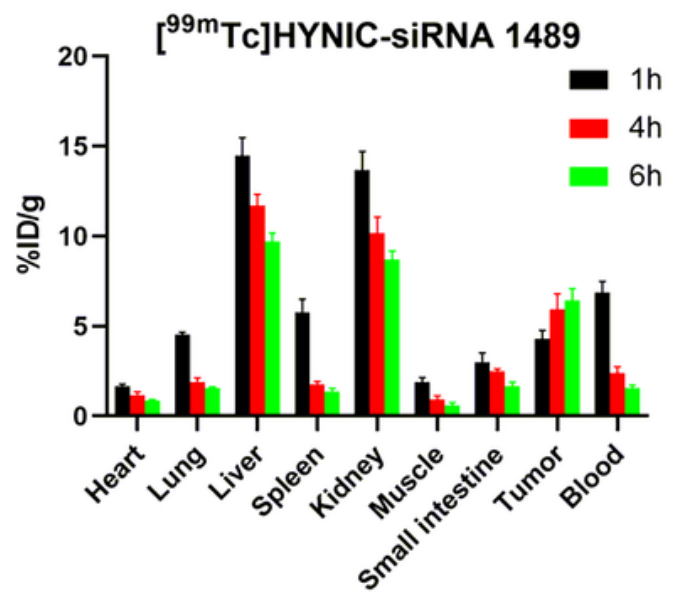

C MCF-7 Block MCF-7

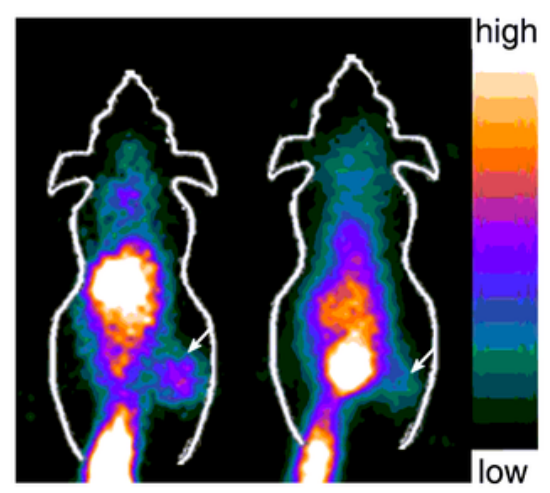

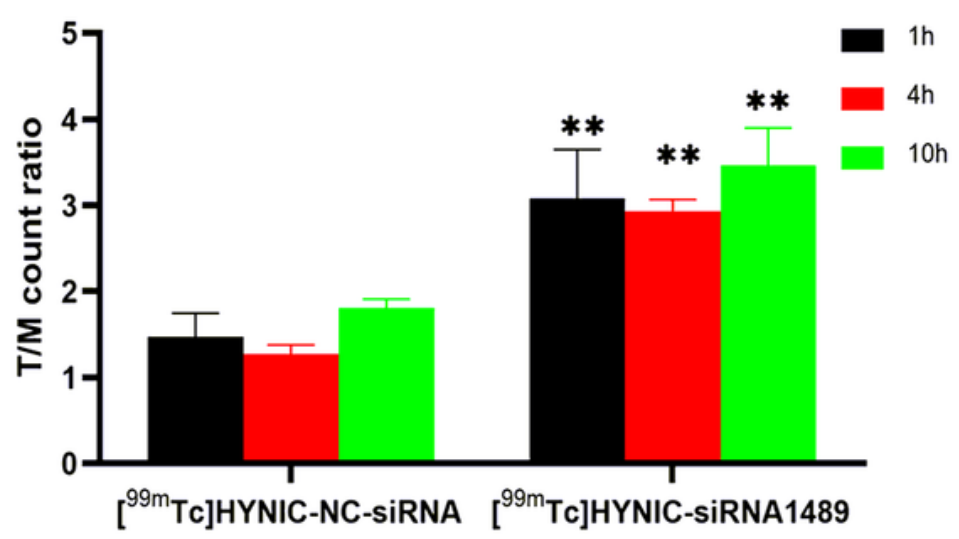
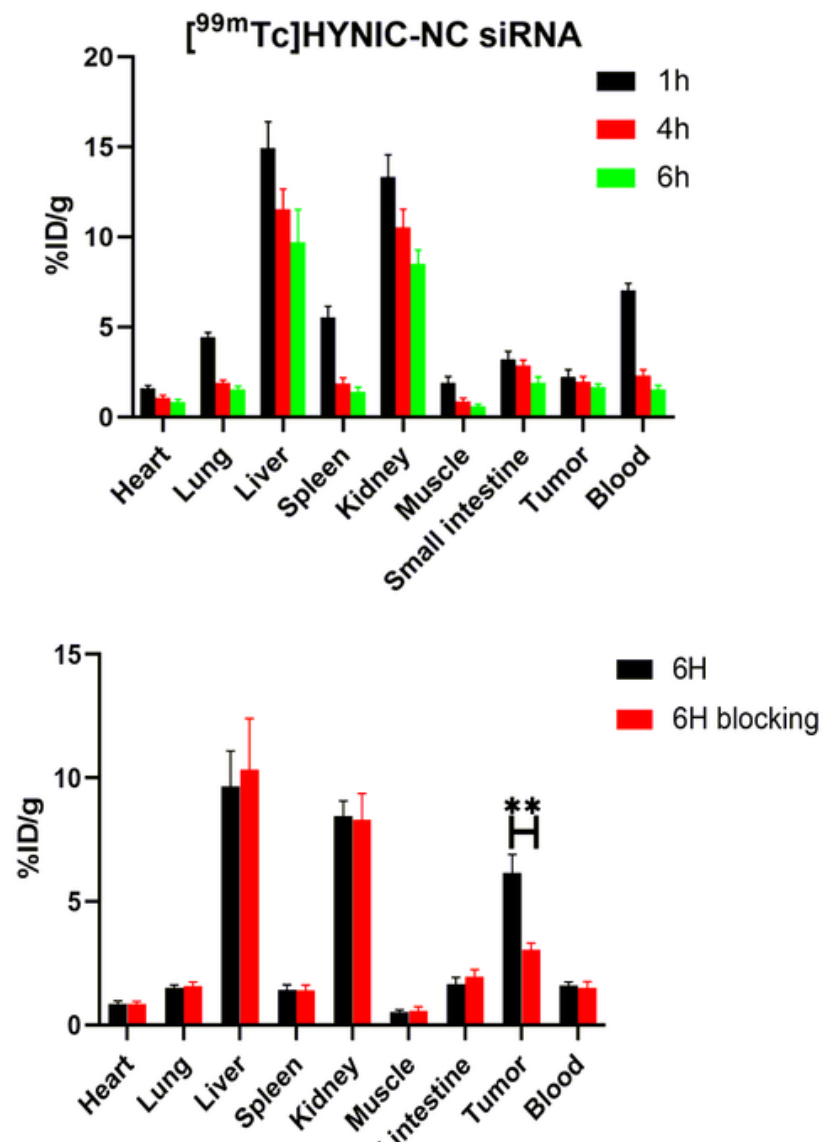

Figure 3 
The imaging study of [99mTc]HYNIC-siRNA in NU/NU mice xenografts.(a)The imaging and ratio of tumor to contralateral muscles(T/M) of mice were injected to [99mTc]HYNIC-siRNA(upper) and [99mTc]HYNICNC siRNA(lower) at different time points.(b)The biodistribution of [99mTc]HYNIC-siRNA(upper) and [99mTc]HYNIC-NC siRNA(lower) in mice.(c)The SPECT images and biodistribution of MCF-7 and BlockMCF-7.Data were presented as mean $\pm S D$ with four independent experiments. ${ }^{*} P<0.05,{ }^{*} P<0.01$ versus the NC group.

\section{Supplementary Files}

This is a list of supplementary files associated with this preprint. Click to download.

- supplementarymaterialsmodified.docx 